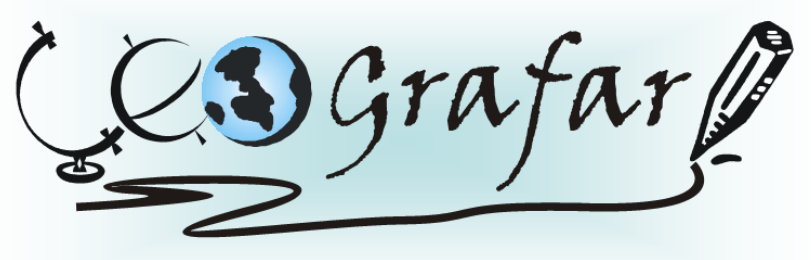

Revista Eletrônica do Programa de Pós-Graduação em Geografia - UFPR

\title{
A MÚSICA NAS AULAS DE GEOGRAFIA: Canções e Representações Geográficas ${ }^{1}$
}

\author{
MARCOS ANTONIO CORREIA ${ }^{2}$
}

\section{RESUMO}

O texto coloca de forma sucinta a experiência empírica realizada no ensino médio, em relação à música nas aulas de geografia: emoção e razão nas representações geográficas. Inicialmente indica a natureza e origem da pesquisa, bem como seu diagnóstico e antecedentes teórico-metodológicos e primeiros contatos com os alunos. Apresenta-se de forma original, pois procura inserir a linguagem musical, por meio de mapas mentais, reformulando a sua aplicabilidade, auxiliando em algumas ressignificações de conceitos e temas geográficos. Foi aplicada a uma 1. a Série do Ensino Médio, em dois momentos: o subjetivo e o Intersubjetivo.

Palavras-Chave: Geografia Escolar, Representações Geográficas, Música, Mapas Mentais.

\section{MUSIC IN THE GEOGRAPHY CLASSES:}

\section{Songs and geographical representation}

\begin{abstract}
The text offers in brief an empirical experience related to music in the Geography classes, developed at the Secondary School: emotion and reason in the geographical representations. To begin with, it indicates the nature and origin of the research and its diagnostic and former theoretical methodology, including its first contact with the students. Its presentation is original due to its search to include the musical language through mental maps, reformulating its applicability, improving

\footnotetext{
${ }^{1}$ Texto apresentado ao Programa de Desenvolvimento Educacional do Estado do Paraná. Com base na Dissertação de Mestrado do autor.

${ }^{2}$ Mestre (Ddo.) em Geografia pela UFPR - Universidade Federal do Paraná.
} 
comprehension of some concepts' meaning and geography themes. This research project was applied in two moments: the subjective and inter subjective, in a First Year Group, at a State Secondary School.

Keywords: School Geography, Geographic Representations, Music, Mental Maps.

\section{INTRODUÇÃO}

\section{O artigo, A Música nas Aulas de Geografia: canções e representações} geográficas, origina-se de pesquisa em âmbito pedagógico e teórico-metodológico, no tocante à disciplina de geografia, realizada no Ensino Básico em seu Nível Médio.

Concernente ao posicionamento político-pedagógico da Lei de Diretrizes e Base da Educação Nacional (LDBEN) 9394/96, assim como dos Parâmetros Curriculares Nacionais - Ensino Médio (PCNEM) e suas respectivas: Diretrizes Curriculares Nacionais para o Ensino Médio (DCNEM) e Orientações Curriculares do Ensino Médio Nacional (MEC-SEB) e Estadual (SEED-PR). Pois esses instrumentos idealizam condições que, na prática, por vários motivos, não estão sendo implementados em sua plenitude, haja vista algumas dificuldades, principalmente, de ordem teórico-metodológica e sua respectiva aplicação. Isso ocorre quando se trata dos alicerces fundamentais, os quais se baseiam na LDBEM.

O trabalho concretiza-se no interior das ciências humanas e sociais, na área da geografia humanista cultural e social, enquadra-se na geografia escolar e das representações no âmbito da pesquisa ação participante. Especificamente, reflete o conhecimento geográfico, desde a estrutura epistemológica do saber, no interior das ciências humanas, em abordagem fenomenológica da percepção à representação espacial, baseada nas representações sociais, demonstrando que a ciência pode inserir o ser humano como sujeito e objeto dos estudos, usando a emoção e a razão na produção, reprodução e ressignificação do conhecimento geográfico.

Sugere intervenção e participação ontológica, ôntica e estética $\square$ por meio da: arte (música/canção), ciência e do senso comum $\square$ do ser humano na organização de espaço vivido em seu cotidiano, usando, preferencialmente, além do racional, elementos criativos e emocionais na elaboração e construção de conhecimentos imprescindíveis à educação formal e integral do educando $\square$ este concebido como 
ator (aluno) passivo e ativo, no palco de sua existência $\square$ principalmente, na sala de aula.

Em relação aos objetivos específicos, procura-se: levar o educando a apreciar a ciência geográfica; provocar a sensibilização e percepção espacial (lugar/Planeta Terra); sugerir atividades de percepção e representação topofílica; levar o educando a intencionalizar suas ações intuitiva, artísticas e estéticas, em relação aos elementos da natureza; levar o educando a elaborar atividades que despertem a estética no espaço vivido; perceber e representar as formas e dinâmicas internas e externas do Nosso Planeta; perceber e representar seu meio ambiente e situar o homem no mundo.

Quanto ao tratamento empírico-metodológico, as atividades realizadas utilizaram-se, parcialmente, de metodologia idealizada por Kozel, adaptada às necessidades da pesquisa em questão e de procedimento concebido pelo pesquisador/professor deste trabalho, a saber: o PIS (Plano Intencional Subjetivo), associado aos Mapas Mentais e sua respectiva DIS (Descrição Intencional Objetiva).

Finalmente, o texto estrutura-se em três partes: na primeira, apresenta breve diagnóstico e natureza da pesquisa, na segunda parte, coloca-se a elaboração teórica e, em seguida, relata-se a aplicação de atividades musicalizadas, subdivididas em momento subjetivo e momento intersubjetivo.

\section{ORIGEM DA PESQUISA}

Além da constatação in loco, por meio de observação ocorrida no dia a dia, da prática educativa no Ensino Básico, da constatação por meio de literatura, basicamente constantes nos documentos oficiais, em nível Nacional e Estadual (PR) e também em outras obras sobre educação, fizeram-se coletas junto aos alunos do Ensino Médio, para verificar a aceitação e o andamento didático-pedagógico do ensino de geografia. Esses instrumentos teóricos e práticos permitem diagnóstico pessimista em relação aos destinos epistêmicos e pedagógicos da geografia.

O estudo parte de observação regular da realidade escolar de várias turmas de ensino básico da Rede Educacional do Estado do Paraná. Ele expressa a necessidade e preocupação de trazer e fazer algo diferenciado em relação às aulas 
de geografia, pois estas, a cada ano que passa, vêm sendo desprestigiadas por expressiva leva de alunos, chegando a ponto de afirmarem, categoricamente, que não gostam e não querem estudar geografia.

O laboratório observacional das atividades foi a 1. Série C do Colégio Estadual José de Anchieta, Núcleo de União da Vitória, Estado do Paraná. E dos 42 alunos matriculados, 35 participaram efetivamente das atividades.

Consta no PPP-CEJA ${ }^{3}$ (2008, p.9-10), que os alunos do Colégio são oriundos, em sua maioria, do centro do Município de União da Vitória e bairros periféricos. Em relação à situação econômica, cerca de $66 \%$ das famílias recebem de 1 a 3 salários e os 34\% restantes vivem com mais de três salários mínimos; estes advêm, principalmente, do setor terciário (comércio) da economia, acompanhado do setor secundário (indústria) e primário, basicamente da agricultura.

$\mathrm{Na}$ busca de informações para constituição de perfil da referida turma, pontuam-se algumas informações constantes no PPP-CEJA (2008, p.10-11), sobre a escolaridade, no qual consta que cerca de $45 \%$ dos pais, dos alunos terminaram o Ensino Básico e 11\% concluíram o Ensino Superior; 69 \% dos pais são casados e $31 \%$ são separados; aproximadamente $75 \%$ do alunos dedicam cerca de 1 hora diária aos estudos; nos períodos de folga a maior parte usa TV e outros aparelhos eletrônicos para seu lazer; grande porcentagem (33\%) dos alunos moram com avós, tios e/ou outras pessoas.

Com esses dados, além de outros, inclusive retirados da própria vivência com os alunos constantes no Projeto Político Pedagógico da escola, pode-se dizer que a turma goza de perfil semelhante a várias turmas de estudantes do interior (principalmente nas Regiões Sul e Sudeste) do Brasil. Estes vivem em contextos culturais semelhantes e estão envolvidos pela mesma estrutura socio-econômica, além de outras características semelhantes, das quais o ensino faz parte, de modo geral, e a geografia, em particular, se apresenta com suas peculiaridades.

Os adolescentes possuem, em média, idades entre 15 e 16 anos, advindos de classe média baixa e estão em contato com vários meios de comunicação e informação, mas, de maneira geral, não trabalham muito bem o conhecimento em si. Outro problema observado, em relação ao dia a dia desses alunos, é certa dificuldade em seus relacionamentos, principalmente, com pessoas mais velhas

\footnotetext{
${ }^{3}$ Plano Político Pedagógico do Colégio José de Anchieta - Núcleo de União da Vitória.
} 
como: os pais, tios, avós e professores.

Além de dados sócio-econômicos, pedagógicos e outros, levantou-se que grande parte dos alunos ouvem música e associam essa prática a outras atividades cotidianas. O que chama a atenção é a grande importância que os alunos dão à música e a utilização de aparelhos eletrônicos no seu tempo interno e externo à escola. Esse aspecto reforça a utilização da música/canção como instrumento auxiliar no processo ensino-aprendizagem.

\section{DIAGNÓSTICO E ANTECEDENTES TEÓRICO-METODOLÓGICO}

Os primeiros contatos com os alunos pesquisados revelaram algumas impressões significativas, estas foram retiradas de enquete que trazia algumas questões como:

1- Estudar para você é ( ) Importante, ( ) Necessário, ( ) Dispensável;

2- Escreva o nome de três disciplinas de sua preferência;

3- Escreva o nome de três disciplinas que você não faz questão de estudar;

4- Escreva o que pensa sobre as aulas de geografia durante sua vida escolar.

Você mudaria algo nas aulas de geografia? Explique.

Este questionamento inicial foi muito importante para constatar algo que algumas pesquisas já revelam e, portanto, confirmaram suspeitas em relação ao ensino de geografia, na qual este pesquisador atua como professor (Colégio José de Anchieta).

No caso da primeira indagação, a grande maioria, cerca de 27 alunos, relatou que o ensino ou a disciplina de geografia é muito importante e necessária para o desenvolvimento das pessoas. Percebeu-se, como pesquisador e professor de geografia, que os alunos admiram os conteúdos geográficos e sabem de sua importância.

Quanto ao item dois, a disciplina de geografia, na turma pesquisada, não obteve boa performance, pois não consta entre as preferidas, ao contrário da disciplina de educação física, por exemplo, que foi a mais votada. Por outro lado, junto com biologia, física, e química, a geografia consta como disciplina que os alunos não fazem questão de estudar.

Principalmente, em relação a esses últimos dados, pode-se constatar certo 
desinteresse dos alunos no caso das disciplinas ditas "duras". Nesses sentido, alguns educadores alertam para certa crise da instituição escolar e, consequentemente, dos saberes geográficos.

Em relação à quarta questão (o que pensa sobre as aulas de geografia durante sua vida escolar? ) alguns alunos afirmaram: “... que o professor não sabia explicar... ele não chega até o aluno... necessidade de complementar a aula com mais material virtual... não vou usar geografia na minha profissão... mais interatividade... mais exercícios valendo nota...não é nada fácil aprender e estudar geografia... mais explicação nas aulas...as aulas deveriam ser diferentes e divertidas... mais dinâmica...mudar o jeito de explicação pelo professor...mais aulas de campo... eu não gosto muito de ter aulas de geografia, mas é um pouco importante, o que vai se fazer, é obrigado estudar...".

É interessante notar que este trabalho, originalmente resultado de atividades implementadas pela SEED-PR (Secretaria de Educação do Estado do Paraná), por meio do PDE (Programa de Desenvolvimento Educacional), foi ampliado a várias escolas do Estado do Paraná com a participação de diversos professores e professoras da Rede Pública de Ensino, visto que tais professores participaram do GTR (Grupo de Trabalho em Rede). Portanto, estabeleceram-se várias atividades vinculadas e coordenadas pelo professor PDE(2008), atreladas ao tema ora descrito.

Portanto, colocam-se algumas impressões de professores do GTR em relação ao que eles (alunos) pensam sobre a aula de Geografia como: "alguns reclamaram que são muitos textos, outros não gostam de fazer mapas... a matéria é chata, enjoativa, que não é necessário estudá-la.... gostariam de ver filmes e fazer passeios....'devido eu nunca ter ligado pra estudar, o aproveitamento dessa matéria é muito baixo ...eu só estudo geografia porque é necessário eu nunca gostei e não entendo... eu não consigo entender muitas coisa, mas procuro me esforçar, é uma disciplina importante ... tem muita explicação as aulas são meio vagas e eu colocaria mais estudo de mapas ... as aulas poderiam ter menos textos e mais exercícios ... deveríamos fazer mais viagens para conhecermos lugares ... as aulas de geografia poderia mudar porque é muita leitura e acaba confundindo um pouco e deveria ter mais interatividade com os alunos ... excursões, passeios no campo para estudar rochas e relevo ... pesquisas na internet da escolas ... maior 
número de aulas", ... trabalho com filmes, músicas e poesias ... mais alegre, porque a aula de geografia é meio tristonha ... legal, mas teríamos que ir passear ... eu mudaria a questões para que ficassem mais fáceis de responder ... aulas mais legais, divertidas e mais engraçadas".

Kaercher (2000, p. 136-8) diz que os alunos pensam que a geografia é coisa da escola e dos professores de geografia. Para chegar a essa conclusão, muito semelhante a preocupações deste artigo, ele relata que o ensino desta disciplina é árido, classificatório, distante da realidade, acentuadamente baseado na memorização, conteudista e muito presa aos livros didáticos, entre outros. No entanto, lembra que essas não são características apenas da geografia instituída na escola, pois atinge todas as outras disciplinas. Por outro lado, repara que esses procedimentos, usados com freqüência, podem anular ou prejudicar o conhecimento praticado no ambiente escolar.

No caso da geografia escolar, no que tange ao ensino, Cavalcanti (2005, p.29) coloca que o referencial teórico das representações sociais aparece no meio acadêmico como artifício para a compreensão de pensamentos na elaboração de conceitos e imagens geográficas, que os jovens realizam em seu dia-a-dia em vários ambientes, inclusive na escola.

O estudo das representações sociais tem, assim, como suporte a vida cotidiana e a atividade cognitiva dos sujeitos que as formam. Essa convicção de que o estudo do conteúdo das representações dos alunos sobre Geografia é um caminho para melhor conhecer o mundo vivido dos alunos suas concepções e seu processo de construção de conhecimento. (...) A Geografia trabalha com conceitos que fazem parte da vida cotidiana das pessoas e em geral elas possuem representações sobre tais conceitos. (Cavalcanti, 2005, p.32)

A pesquisa ora realizada não desabona a ciência clássica de cunho positivista, mas procura abrir outras possibilidades aos saberes humanos e seu respectivo ensino. Nesse sentido, é interessante observar as ideias merleaupontyanas.

Tudo aquilo que sei do mundo, mesmo por ciência, eu o sei a partir de uma visão minha ou de uma experiência do mundo sem a qual os símbolos da ciência não poderiam dizer nada. Todo o universo da ciência é construído sobre o mundo vivido, e se queremos pensar a própria ciência com rigor, apreciar exatamente seu sentido e seu alcance, precisamos primeiramente despertar essa experiência do mundo da qual ela é expressão segunda. A ciência não tem e não terá jamais o mesmo sentido de ser que o mundo percebido, pela simples razão de que ela é uma determinação ou uma explicitação dele. (Merleau-Ponty, 1999, p. 03). 
A pesquisa situa-se na área da geografia cultural humanista, visando aplicações metodológicas na elaboração e disseminação dos conteúdos geográficos, portanto enquadra-se, também, na pesquisa geográfica escolar Geografia Escolar $\square$ qualitativa, descritivo-empírica, construída por teoria embasada nas ciências humanas, as quais oferecem aporte a sua efetiva aplicação prática. No tocante à geografia cultural, Claval relata:

\begin{abstract}
O mundo real é duplicado por mundos imaginados, que são indispensáveis para lhe dar sentido e aparecem freqüentemente como mais autênticos do que aqueles que nossos olhos desvelam. Esses algures afloram em certos lugares. Se a geografia cultural se dedica à experiência que os homens têm do mundo, da natureza e da sociedade, ela deve partir daquilo que os seus sentidos Ihes revelam. (...). A cultura não fala somente do espaço; ela fala também da natureza. Ela o toma simultaneamente como um meio a dominar para extrair aquilo que é necessário à existência e como um conjunto carregado de sentidos. A paisagem retém a atenção, uma vez que é o suporte das representações. (Claval, 1997, p.95-102).
\end{abstract}

Os autores acima relatam que o mundo vivido é diferente do mundo enquadrado no saber sistematizado cientificamente e, de certa forma, atribuem à cultura e suas manifestações ocorridas no espaço natural, do qual resultam em paisagem geográfica. Essas ideias, direta ou indiretamente, podem apontar categorias ao estudo espacial.

Segundo Tuan (1980, p. 05), o lugar é a categoria chave à geografia e indica que o termo topofilia é a ligação afetiva entre o sujeito e o lugar ou a natureza. As manifestações são de várias ordens, evolvendo principalmente a estética ou sentimentos estéticos, assim como sensações e sentimentos relacionados ao meio ambiente mais próximo, o qual é, em última análise, o meio ambiente de subsistência humana. Pois as pessoas se concentram para as questões ambientais que Ihes dão segurança, sustento e satisfação em sua vida. Portanto, os seres humanos sonham e imaginam lugares ideais. Mesmo a Terra não sendo a morada final de toda a humanidade, como pensam alguns, existe uma relação íntima com o planeta, inspirando afetividade a determinado lugar.

Segundo Tuan (1983, p.83), a familiaridade com o espaço é que o caracteriza como lugar e na sua elaboração conceitual, a experiência e o contato topofílico proporcionam novas abstrações espaciais, as quais poderão ser transformadas e comunicadas mediante de simbologias, palavras e imagens, montando capacidades geográficas configuradas em conhecimento espacial.

Buttimer (1985, p.171) continua dizendo que os geógrafos sabem da ação 
eficaz dos aspectos naturais e culturais e que estes interferem na experiência, modificando a noção terminológica de mundo e espaço. Sendo o mundo cotidiano uma concentração de atividades dinâmicas vividas de forma holística, até que o ser que pensa comece a inferir reflexões sobre ele.

As representações sociais transferidas e adaptadas para o ambiente pedagógico trazem excelente instrumental metodológico e didático-pedagógico na aplicação dos conteúdos geográficos. Nesse sentido, André (1990, p.196) relata que as representações no ensino de geografia decorrem de trabalhos de investigações geográficas e da geografia da percepção. Relata que Bailly retraçou bem a gênese desses trabalhos que parecem calcar-se sobre o termo recente de representação espacial, que evidencia o social e o individual no real. Por outro lado, o uso das representações decorre, igualmente, da aplicação às ciências sociais do conceito de representação social. Concluindo, diz que o conceito de representação espacial ainda é subaproveitado e mal utilizado no ensino de geografia.

Para situar a geografia no contexto das representações sociais e em certa medida, nas apreensões pessoais, é oportuno lembrar as idéias de Moscovici quando diz:

(...) Sempre e em todo o lugar, quando nós encontramos pessoas ou coisas e nos familiarizamos com elas, tais representações estão presentes. (...) podemos afirmar que o que é importante é a natureza da mudança, através da qual as representações sociais se tornam capazes de influenciar o comportamento do indivíduo participante de uma coletividade. É dessa maneira que elas são criadas, internamente, mentalmente, pois é dessa maneira que o próprio processo coletivo penetra como o fator determinante, dentro do pensamento individual. (...) Pessoas e grupos criam representações no decurso da comunicação e da cooperação. (...) Ao criar representações, nós somos como o artista, que se inclina diante da estátua que ele esculpiu e a adora como se fosse um deus. (Moscovici, 2005, p. 401).

André (1990, p.199) destaca Jodelet, quando coloca a comparação entre representações espaciais em contraponto com o saber científico, que perde qualquer significado na medida em que a elaboração das paisagens pelos homens procede das representações: "a paisagem humanizada" é nada menos e nada mais que apenas a expressão espacial das decisões dos homens. Independente da discussão da cientificidade ou não das representações, o interessante é que o apelo às representações permite enraizar os conhecimentos sobre a experiência diária dos alunos. Ela também oferece abertura ao pensamento racional e modelizante, porque uma representação justapõe duas funções: uma função de organização e uma 


\section{função para a apropriação pessoal.}

Com efeito, as representações aparecem como um meio para apreender as divergências sociais, divergências de práticas, de percepções do espaço, os quais, por meio das representações dos alunos, os "atores" do meio social e no caso educacional, se mostram pertinentes. André (1990, p.213-14) continua dizendo que os modelos gráficos $\square$ na pesquisa: concepção sígnico-imagética mental e/ou mapas mentais $\square$ são as expressões sintéticas do pensamento, e que o professor é quem conduz os seus alunos à uma representação daquilo que é necessário saber sobre algum conteúdo. La pédagogie et la didactique ne peuvent ignorer ce rôle de l'imaginaire et c'est particulièrement vrai pour la géographie, discipline de l'imaginaire spatial'. (André, 1990, p.13)

Olhando pelo lado pedagógico e didático da geografia humanista cultural, fica mais fácil entender e até de justificar a subjetividade em relação ao conhecimento. Já, pelo lado científico, as críticas são contundentes, mas de certa forma precipitadas, pois o tema deve ser debatido com mais afinco e rigor. Neste caso, pode-se citar as palavras de Kozel (2002, p.228), quando diz que, para se perceber a subjetividade das pessoas, tem-se que remontar as representações mundanas delas. Sendo assim, as representações tornam-se fundamento das ações, as quais pressupõem conhecimentos e não somente um processo de aprendizagem.

Segundo Pontuschka (1999, p.118-9), as metodologias utilizadas pela geografia tradicional, não dão conta de estudar e explicar o espaço geográfico globalizado pelo capitalismo monopolista, o qual cada vez mais aumenta seu grau de complexidade. Contudo, na escola, é importante notar que o foco foi alterado, isto é, o aluno passa a ser o centro da atividade educacional, isso ocorre a partir da Escola Nova, consubstanciada no estudo da obra de Jean Piaget, por volta de 1960, quando os educadores entraram em contato com a psicologia da aprendizagem.

Na obra, O Humanismo na Geografia, Bailly; Scariati (1990, p.156-61), junto a outros pensadores concluem que a perspectiva humanista não é mais uma gaveta da geografia, e, sim, uma nova forma de conceber as manifestações geográficas, pois além dos pensamentos racionais, pode-se conceber a lógica do sensível e do subjetivo vividos no cotidiano.

\footnotetext{
${ }^{4}$ A pedagogia e a didática não podem ignorar a lei do imaginário e isto é particularmente verdadeiro para a geografia, disciplina do imaginário espacial. (André, 1990, p.13, tradução nossa)
} 
Nesse contexto, a subjetividade no ambiente educativo é fundamental, e isso pode ser praticado por meio da percepção individual e das representações, juntamente com teorias educacionais e outras elaborações que evocam a emoção, a estética e a criatividade no processo ensino-aprendizagem e sua interdisciplinaridade, enfocando os saberes geográficos no cotidiano do educando.

Bailly (1995, p.10), quando se reporta ao subjetivo de onde vem o imaginário e a representação, diz que esta é constantemente descartada por causa de nossa identidade racional cartesiana, a qual exalta a objetividade e o pensamento funcional e desdenha toda a manifestação subjetiva. Por esse caminho, o autor tenta aproximar o ensino da geografia à ciência, atitude que é compartilhada na elaboração deste artigo. Isso é observado quando estimula a ligação do imaginário ao conteúdo científico e seu respectivo conteúdo trabalhado no ensino de geografia. Na sequência, diz que o conteúdo geográfico sistematizado não é tudo e o subjetivo e as representações sociais, assim como o imaginário, devem estar em estreita afinidade com o saber científico. 
Figura 1 - Mapa Conceitual da Pesquisa ${ }^{5}$

REPRESENTAÇÃO E ENSINO A MÚSICA NAS AULAS DE GEOGRAFIA:

Emoção e Razão nas Representaçōes Geográficas

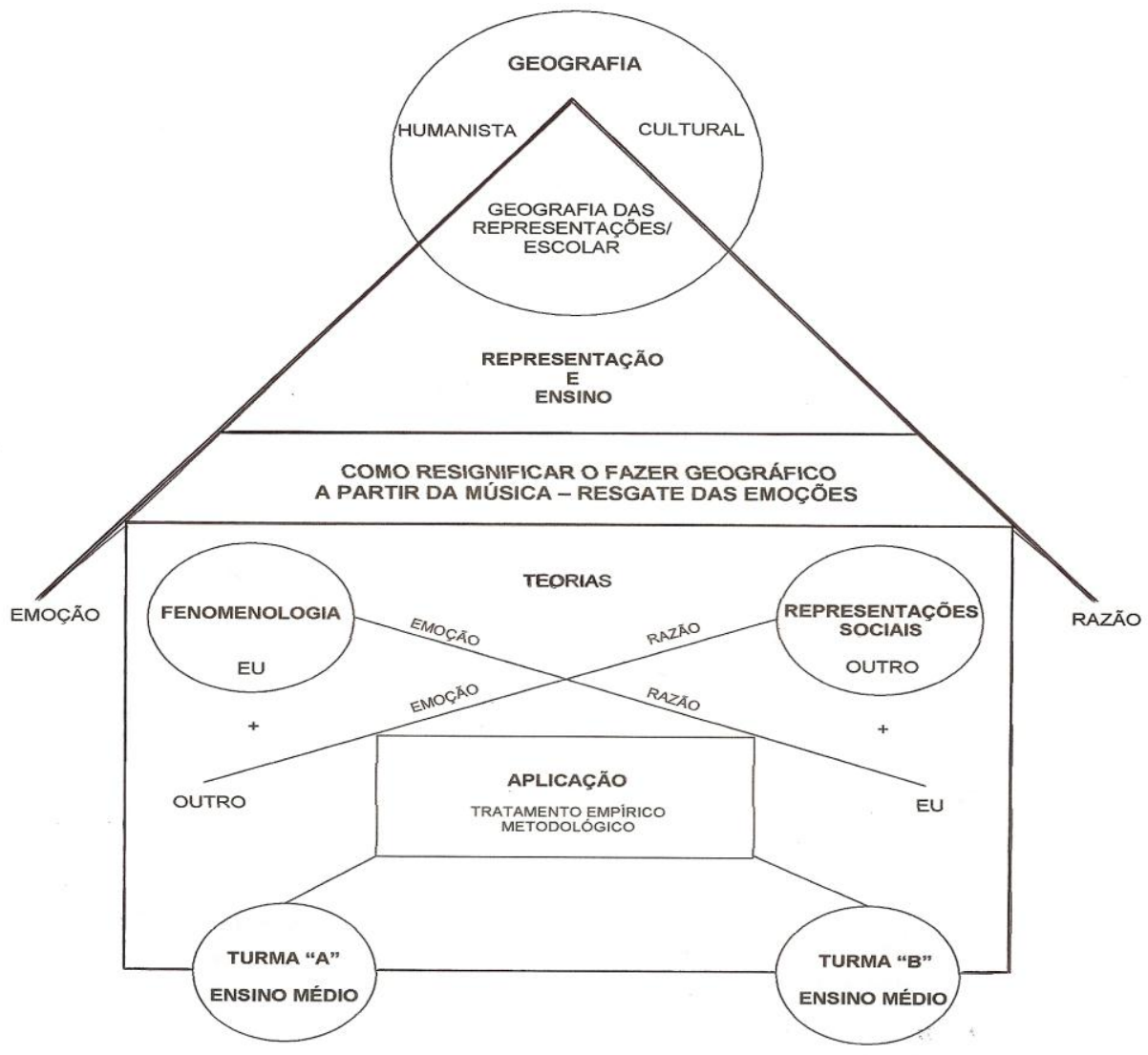

FONTE: Organizado por CORREIA - (Concebido para Dissertação em 2008), 2009.

\section{A MÚSICA NAS AULAS DE GEOGRAFIA}

O texto procura inserir a música de forma diferenciada, reformulando sua aplicabilidade, auxiliando em algumas ressignificações de conceitos e temas geográficos, pois seu conteúdo artístico e racional pode mudar o foco do ensinoaprendizagem de qualquer saber, e, no caso específico da geografia, ela se concatena harmoniosamente, possibilitando uma atitude fenomenológica e das representações compatíveis com o momento pedagógico vivenciado pelo educando na elaboração dos conteúdos geográficos.

\footnotetext{
${ }^{5}$ Mapa conceitual elaborado pelo autor (Correia, 2009, p.32). Serviu de modelo teórico-metodológico para o presente artigo (PDE-2008/2009).
} 
Por outro lado, promove a apreensão diferenciada em relação aos objetos geográficos, proporcionando uma atitude fenomenológica, materializada em representações individuais e coletivas (sociais), ocasionando respectiva descrição, concebida individualmente de maneira subjetiva, contribuindo à elaboração dos conceitos geográficos e práticas educativas da disciplina.

Geograficamente as concepções e categorias topofílicas ${ }^{6}$ servem de pontos de partida às representações espaciais concebidas e sistematizadas durante a elaboração e disseminação dos conhecimentos tratados no processo ensinoaprendizagem.

Originalmente, a pesquisa parte de questão científico-pedagógica, pois notouse a necessidade de equilibrar os alicerces educacionais constantes nos PCNs e previstos nos fundamentos educacionais da LDBEM (9394/96). Pois nesse documento, que rege a educação nacional, registram-se alicerces que servem como objetivos gerais a serem atingidos por meio de práticas pedagógicas. Estes apresentam quatro formas de aprenderes, a saber: conhecer, fazer, ser e viver; mas ressalva-se que os aprenderes: conhecer e fazer sempre figuraram e figuram até hoje em primeiro plano, no Sistema Educacional Brasileiro, por outro lado, o ser e o viver (conviver/viver com) não tiveram a mesma oportunidade.

No ensino de geografia, essa disparidade também ocorre acompanhada de desgaste teórico e didático-pedagógico, no tocante ao fazer geográfico epistêmico e educativo, o qual se apresenta, aos educandos, de forma dilapidada e pedante, como identificado por alguns autores. Nesse sentido, propõe-se uma retomada diferenciada dos conteúdos escolares geográficos, buscando-se a renovação do sentido e dos conteúdos geográficos por meio da ressignificação do fazer geográfico a partir da música, pois ela traz o conteúdo racional e, principalmente, emocional; o que se espera é dinamizar e sintonizar a emoção e razão, pois suas naturezas são indissociáveis e imprescindíveis ao conhecimento humano.

A música auxilia na aprendizagem de várias matérias, entre elas a geografia. Ela é componente histórico de qualquer época, portanto oferece condição de estudos na identificação de questões, comportamentos, fatos e contextos de determinada fase da história, assim como seu referencial geográfico. Os estudantes podem apreciar várias questões sociais e políticas, escutando

\footnotetext{
${ }^{6}$ Principalmente: lugar, paisagem e região.
} 
canções, música clássica ou comédias musicais.

\begin{abstract}
O professor pode utilizar a música em vários segmentos do conhecimento, sempre de forma prazerosa, bem como: na expressão e comunicação, linguagem lógico-matemática, conhecimento científico, saúde e outras. Os currículos de ensino devem incentivar a interdisciplinaridade e suas várias possibilidades. (...) A utilização da música, bem como o uso de outros meios, pode incentivar a participação, a cooperação, socialização, e assim destruir as barreiras que atrasam a democratização curricular do ensino. (...) A prática interdisciplinar ainda é insípida em nossa educação (Correia, 2003, p.84-85).
\end{abstract}

A importância, função e natureza da música estão presentes em todas as indicações legais e nos fundamentos teórico-metodológicos constantes nos documentos norteadores da educação brasileira e em suas respectivas unidades federativas, a exemplo do Estado do Paraná, o qual relata que:

A música no contexto escolar, defendida nessas Diretrizes, objetiva a educação dos sentidos e não está dissociada do lugar onde é composta e interpretada nem está desarticulada dos valores de um determinado grupo social. Exemplos disso são os textos de canções do repertório de cultos religiosos e de manifestações de cunho político e social. (Paraná-DCE, 2007, p.43).

\title{
4.1 APLICAÇÃO DE ATIVIDADES MUSICALIZADAS
}

A aplicação foi dividida em dois momentos distintos. No primeiro momento Subjetivo $\square$ concentrado no $1^{\circ}$ semestre de 2009; buscou-se captar e explorar as emoções dos pesquisados, e em seguida fazer com que eles demonstrassem esse processo mental (mapas mentais). Utilizou-se para tanto, o desenho (ilustrações O desenho foi a forma elementar de idealizar e ilustrar as primeiras concepções sígnico-imagéticas dos alunos; texto escrito foi utilizado quando das descrições subjetivas e objetivas, elaboração de projetos para as atividades, comentários e outras manifestações dos sentimentos e pensamentos dos alunos. Aliás, esses artifícios foram usados em todo o processo aplicativo da pesquisa, tanto no primeiro como no segundo momento.

Com essas imagens, conseguimos retirar algumas informações interessantes ao processo didático-pedagógico experimentado por eles, junto com seu professor regente em seu cotidiano. As imagens levantadas foram concebidas a partir da audição de duas canções, escolhidas pelo professor/pesquisador, e que têm, em 
sua estrutura textual e musical, os conteúdos geográficos trabalhados ao longo do ano letivo, a saber: "o Lugar e a Terra."

Em relação às primeiras atividades, para testar instrumentos e procedimentos, foram selecionadas duas músicas que expressam o espírito da pesquisa, por sua estrutura musical, relacionadas aos conteúdos geográficos explorados nas séries iniciais do ensino médio, a saber: "Canto do Povo de um Lugar"7 de Caetano Veloso e "O Sal da Terra"8, música de Beto Guedes, além de outras escolhidas e trabalhadas pelos alunos. Essas canções e seus conteúdos artísticos e geográficos, mediados pela estética, subjetividade, objetividade e intersubjetividade, foram contextualizadas, materializadas e apresentadas em forma de várias atividades pedagógicas criadas pelos próprios alunos.

\section{Quadro 1 - Canções trabalhadas - Base para os mapas mentais}

\section{1- Canções Propostas pelo Professor:}

- O Canto do Um Povo de Um Lugar - Caetano Veloso

- O Sal da Terra - Roupa Nova

2- Canções Escolhidas pelos Alunos da 1.a Série do Ensino Médio

- A Natureza - Zé Ramalho

- Pantanal (Sagrado Coração da Terra) - Almir Sater

- Aquarela - Chimarruts

- Quando a Chuva Passar - Ivete Sangalo

- Vida Boa - Victor e Leo

- Meu Reino Encantado - Daniel

- Bem-Te-Vi - Zé Fortuna \& Pitangueira

- Casinha - Armandinho

- Planeta Água - Guilherme Arantes

FONTE: Dados da Pesquisa (Organizados pelo autor), União da Vitória-PR, 2009.

\footnotetext{
${ }^{7}$ Esta canção inspira sentimento de pertencimento a um lugar no Planeta Terra e induz, metaforicamente, à idéias de: começo, meio e fim, importante quando se trabalha textos (neste trabalho: descrições subjetivas, objetivas, intersubjetivas e depoimentos), além de projetos idealizados pelos alunos para realização de atividades individuais e coletivas.

${ }^{8}$ A canção, "O Sal da Terra", provoca reflexão sobre as condições da Terra, da natureza e seus elementos.
} 


\section{Quadro $2 \square$ Metodologia Kozel adaptada às atividades didático-pedagógicas}

\section{1 - Interpretação quanto à forma de representação dos elementos na imagem;}

aparecem na imagem como ícones diversos, letras mapas, linhas, figuras geométricas etc...

2 - Interpretação quanto à distribuição dos elementos na imagem;

como as formas estão dispostas na folha. Por exemplo: aparecem isoladamente, horizontalmente, de forma circular, dispersas, em quadros e em perspectivas.

3 - Interpretação quanto à especificidade dos ícones;

- representação dos elementos: da paisagem natural, da paisagem construída, dos elementos móveis dos elementos humanos

4 - Apresentação de outros aspectos ou particularidades:

o que os mapas mentais e as atividades podem mostrar além dos elementos colocados nos quesitos anteriores.

- Conscientização em relação aos problemas socioambientais e à natureza em geral; o cotidiano do aluno (ser humano) em seu lugar (mundo vivido); grau de percepção e representação topofílica; identificação de categorias e elementos geográficos; outras formas de percepções e representações do espaço geográfico;

- OBS: o quarto quesito foi acionado sempre quando não se encontrou forma de enquadramento mais efetivo nos quesitos $1 .^{\circ}, 2 .^{\circ}$ e $3 .^{\circ}$ da metodologia Kozel e também para auxiliar nas atividades didáticopedagógicas dos alunos, principalmente, nos primeiros trabalhos centrados na audição das canções: O Canto do Povo de um Lugar e O Sal da Terra.

FONTE: Organizado pelo autor, com base nos quesitos da Metodologia Kozel.

\section{Quadro $3 \square$ PLANO9: Dados, Características - Atividades (PIS e Mapas Mentais)}

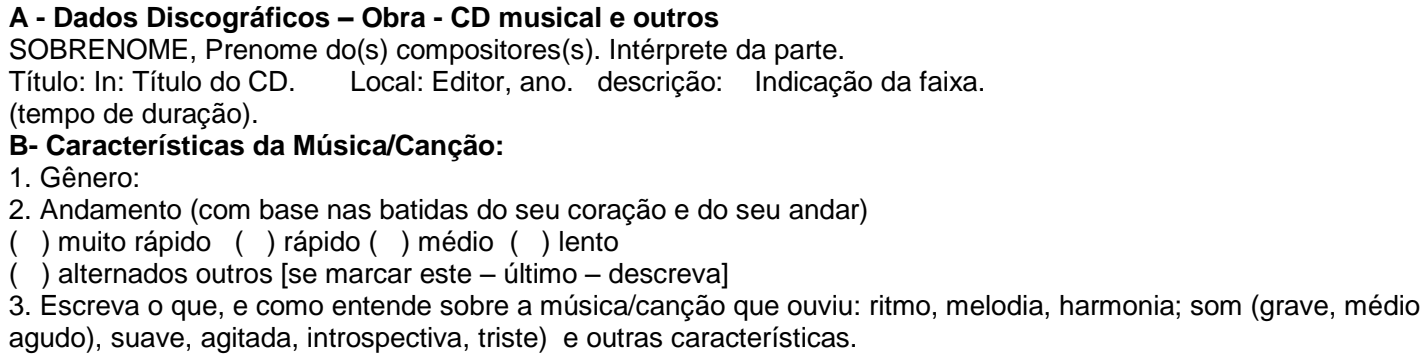

elabore texto (conteúdo geográfico) baseado na música/canção; nas aulas e pesquisa bibliográfica.

b) Concepções Sígnico-Imagéticas:

represente por meio de: imagens, desenhos, mapas, figuras, cartazes, maquetes, painéis e outros) o que aprendeu (apreendeu).

FONTE: Dados da Pesquisa (Organizados pelo autor), União da Vitória-PR, 2009.

O quadro (01) acima mostra as canções já comentadas e traz algumas canções sugeridas e trabalhadas pelos próprios alunos. Juntamente com os quadros (02 e 03), completam as ações metodológicas utilizadas nas interpretações mentais desenvolvidades pelos alunos pesquisados.

\footnotetext{
${ }^{9}$ Metodologia idealizada e aplicada pelo autor por acasião de sua dissertação apresentada em 2009.
} 
Figura 2 - A natureza

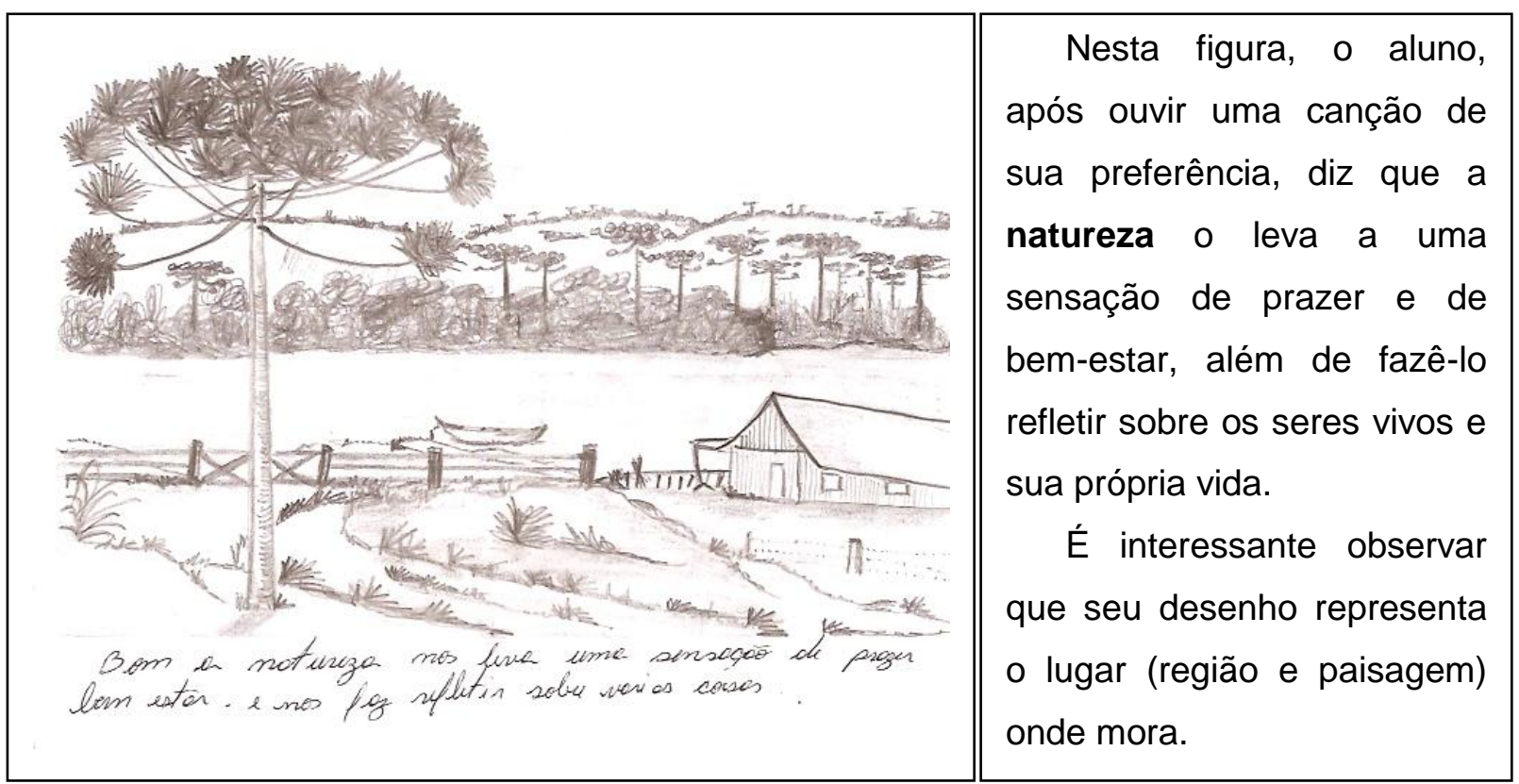

FONTE: Dados da Pesquisa, União da Vitória-PR, 2009 - Aluno 1.ㄹ Série

Figura 3 - Comentário da atividade

O aluno diz que gostou da atividade, pois ela the deu oportunidade para escrever e desenhar algo que ele estava sentindo e não conseguia representar.

A audição de uma canção foi a propulsão emocional importante para a elaboração deste trabalho.

O aluno diz,"Gostei muito, pois essa atividade foi uma coisa muito legal, pois além de estarmos apreendendo por outros meios... escrita e desenho, coisas que eu nunca fazia"

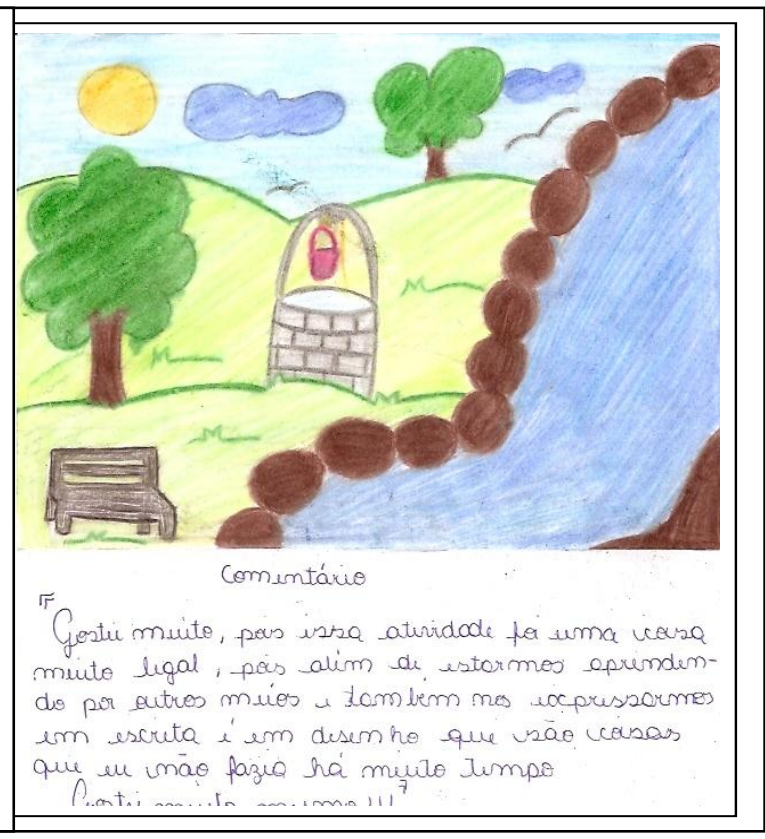

FONTE: Dados da Pesquisa, União da Vitória-PR, 2009 - Aluno 1. a Série 
Figura 4 - Reflexão sobre o meio ambiente

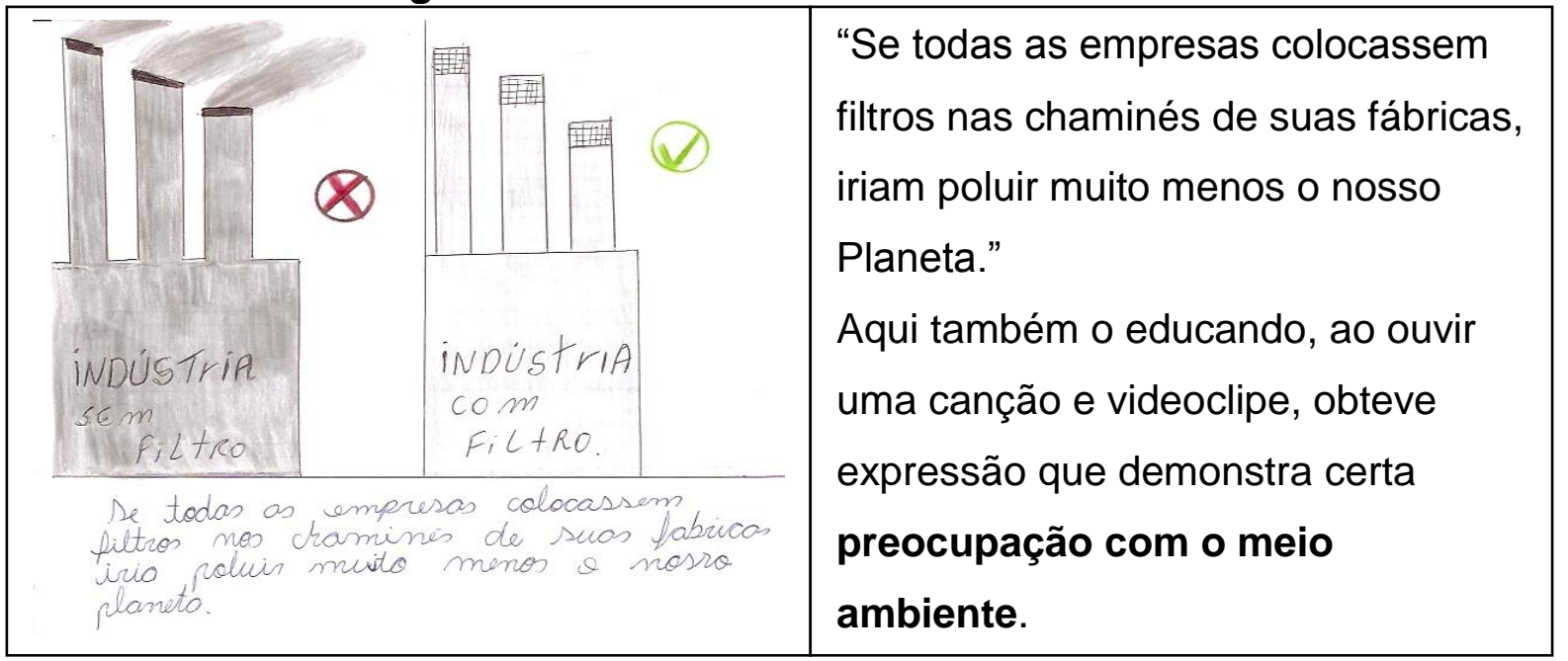

FONTE: Dados da Pesquisa, União da Vitória-PR, 2009 - Aluno 1.ㄹ Série

As figuras (2,3 e 4) foram selecionadas, entre várias, para demonstrar ou pelo menos dar uma ideia da elaboração metodológica utilizada e dos resultados positivos advindo destas.

\section{Quadro 4 - Impressões dos alunos após ouvirem as músicas 'O canto do povo de um lugar' e 'O sal da terra'}

A musica fala no mundo como está que temos que cuidar, com a letra da música é possível deixar a mente fluir e imaginar um mundo melhor sem problemas, é possível sentir essa sensação. ... Terra, lugar, meio ambiente, sociedade, ar, clima, natureza, país, mar, vegetação, água... É uma música que nos alerta dos problemas que nós humanos estamos causando na nossa casa planeta Terra. A canção traz muita emoção pois ela transmite a realidade que estamos vivendo. Eu penso que essa musica devia ser transmitida ao maior número de pessoas possível para se conscientizar de que se não cuidarmos da Terra nós também vamos morrer.

... fala do mundo de amanhã, se as desgraças que estão ocorrendo vão continuar no futuro, será que o futuro dos meus filhos, netos, bisnetos, ainda terá salvação? Mostrou imagens de vegetação, lindas paisagens que nossa natureza tem, planícies, planaltos, montanhas. Hoje em dia muitas pessoas já não tem acesso a esse lazer que é um dom precioso que Deus deixou a nós, mas o homem nem está aí em preservar. A harmonia desta musica nos faz meditar e dar valor a natureza, as espécies em que nela vivem. Tanto a musica quanto a natureza nos faz relaxar, o ser humano precisa de um tempo para o lazer, principalmente quem mora em um centro de uma cidade com muita agitação, quer descansar e relaxar... mostra como existe lugares diferentes, poluídos que não é só aqui que tem poluição e destruição; Terra - está pedindo socorro pois está sobrecarregada; Meio-ambiente- onde vivemos, tudo que está em nosso redor; Sociedade - é a população que vive nesse meio.

A musica traz imagens de lugares bonitos do planeta Terra, traz conceitos do que devemos preservar para o futuro, também, fala de floresta e vegetação... sobre o planeta Terra, como o assunto camada de ozônio, fala também sobre as florestas e a vegetação....Poucas pessoas têm o privilégio de ter tudo e as pessoas que tem não sabem ajudar ou dar ao próximo. Alguém que tem pouco tem mais amor do que quem tem muito. ...Na musica apresenta muitas paisagens como a natureza, os animais, as pessoas... devemos preservar o nosso planeta; a emoção me deu uma sensação que eu tenho que preservar e devemos nos unir e fazer um mundo melhor. ...Com o tema camada de ozônio, florestas e a vegetação....A idéia é unir forças para um planeta melhor. Busca de soluções, contra a fome, miséria, violência, destruição. Pedindo pela paz e amor, vida nova onde a felicidade está ao nosso lado e a Terra é o nosso chão. Precisamos arrumar como se fosse nossa casa. A preocupação com o futuro da humanidade diante de tantos problemas nos diz que é hora de contribuir com a preservação através da mobilização desses graves problemas ambientais.

A Terra , o espaço, o lugar onde vivemos, as diferentes classes sociais, as formas de vida e como é lindo esse planeta azul, o mais lindo de todos... Penso na natureza, no céu azul, no sol, no mar... sobre a Terra, em todo, sobre as necessidades do mundo, transmite um pensamento humanitário. O mundo precisa de ajuda....Como é a vida no planeta Terra, o que temos que fazer para preservar a vida, cuidar do planeta, várias paisagens, o nascimento da vida. O que acontece com o planeta, com os impactos da atividade humana. Fala sobre as guerras, opressões; conscientiza para que se a Terra morrer os homens morrerão também, então temos que cuidar do que temos.

A musica tratou muito do meio ambiente e sociedade, diz que quanto mais juntarmos forças mais rapidamente mudaremos a nossa situação, falou da água e da Terra no geral. A música traz um sentimento de que devemos todos juntos proteger as menores riquezas e vencer problemas e preconceitos da sociedade.

FONTE: Dados da Pesquisa, União da Vitória-PR, 2009 - Alunos 1.a Série 
Quadro $5 \square$ Conteúdos e Objetivos

Os objetivos observados e estudados com auxilio de canções foram:

1 - A Geografia como ciência - percepção e representação espacial;

2 - O Ser humano (aluno-ator social) em seu espaço vivido no cotidiano;

3 - Planeta Terra-Lugar: agentes internos e externos $\square$ percepção espacial;

4 - Lugar: dimensão cultural $\square$ aspectos topofílicos

5 - Elementos da Natureza $\square$ aspectos estéticos;

6 - O meio ambiente: dimensão socioambiental: percepção e representação.

FONTE: Dados da Pesquisa (Organizados pelo autor), União da Vitória-PR, 2009.

No segundo momento, $\square$ Intersubjetivo $\square$ concentrado no $2^{\circ}$ semestre de 2009, foram trabalhados os conteúdos, constantes no quadro (05) acima que tratam: da geografia como ciência (percepção e representação espacial); do espaço vivido no cotidiano (do aluno: ator social); agentes internos e externos; aspectos topofílicos (dimensão cultural); elementos da natureza (relevo, rochas, solos, mares, rios, lagos, fauna flora e outros); meio ambiente (ação antrópica) e sua dimensão socioambiental: percepção e representação.

Nesta fase, seguindo-se o mesmo padrão metodológico, foram realizadas atividades em grupos, buscando a intersubjetividade; explorou-se a criatividade, subjetividades expressas pela emoção e razão dos alunos. Após várias atividades subjetivas e individuais, demonstradas anteriormente, destacamos 0 compartilhamento de suas descobertas com seus pares e a organização de várias outras atividades didático-pedagógicas.

Aqui destacam-se algumas impressões do grupo "Qualquer pessoa que ouça a canção "Meu reino encantado", interpretada pelo cantor Daniel, e que tenha laços com a vida interiorana, logo a relaciona com imagens de lugares do interior de nosso país. ... Hoje tudo é diferente, a paisagem mudou. As densas matas de pinheirais deram lugar a imensas lavouras, as lagoas secaram, os rios tornaram-se estreitos e os carros de boi não existem mais."

Também, partindo da canção, o grupo faz a seguinte avaliação quanto à descrição objetiva: "Nosso planeta Terra como o conhecemos hoje no meio físico, está, sempre, em constantes transformações, seja pela ação das chuvas, dos animais que no seu ir e vir, atrás de alimentos, transforma o seu território, do homem industrial que usa os recursos naturais para a aquisição de capital necessário a sua sobrevivência e das pessoas que dele dependem, do homem urbano que expande 
cidades com suas construções e alterações do meio geográfico, do homem rural que também transforma o seu espaço"

Os alunos que fizeram trabalhos com desenhos e pinturas de mapas passaram pelo mesmo processo dos grupos anteriores e fazem a seguinte colocação: "não gostávamos de geografia, mas sempre gostamos de música, tivemos a sorte de ter um professor que as uniu. A geografia ficou mais fácil, pois a maioria das pessoas gosta de canções e foi com elas que aprendemos a ouvir os sons da natureza e entendê-la. As aulas ficaram mais fáceis, pois começou a envolver os sentimentos e as emoções; viajamos pelo universo que ficou mais perto de nós. Aprendemos várias coisas como a importância de cuidar da Terra e de tudo que faz parte dela."

\section{CONSIDERAÇÕES FINAIS}

O artigo ora realizado com base na pesquisa (PDE), aponta que a música continua sendo ótimo componente metodológico e pedagógico, podendo ser utilizada em qualquer momento do processo ensino-aprendizagem.

No início, algumas dificuldades foram identificadas. Estas estão em contexto amplo, e as justificativas apontadas por alguns destacam como origem: as mudanças no projeto humano, que entram em choque com princípios estabelecidos desde a renascença. Nesse período, entre outras coisas, privilegiou-se a razão em detrimento da emoção; outros apontam para crise em algumas estruturas humanas como a ética, a estética, aspectos políticos, sociais, econômicos e culturais, além de alterações institucionais, a exemplo da família, da religião, da escola, entre outras.

As metodologias ligadas ao ensino, de modo geral, apresentam-se um tanto desgastadas, é o que se pode observar no diagnóstico deste trabalho e também nas pesquisas realizadas por alguns estudos. Aparentemente os alunos não conseguem permanecer muito tempo nos bancos escolares, sem que ocorra a variação no tratamento metodológico utilizado pelas diversas disciplinas trabalhadas no sistema educacional.

Contrapondo-se às primeiras impressões, diagnosticadas, pode-se dizer que, a maioria dos alunos reconsiderou pensamentos negativos e arredios que tinham em relação às aulas de geografia, pois as vivências em relação à apreensão de 
conteúdos, por meio da música provocaram melhorias na prontidão e aceitação das proposições dos conteúdos sugeridos no dia a dia da sala de aula. Praticamente a totalidade da classe se empenhou nos dois momentos (subjetivo e intersubjetivo) aplicados no ano letivo de 2009.

Os mapas mentais, tanto no momento subjetivo e intersubjetivo, desencadeados pelos textos musicais, tiveram papéis semelhantes, mas com dimensões diferenciadas, pois o primeiro liberou o indivíduo e sua idiossincrasia e deixou que sua imaginação, por meio das canções intencionalizadas pelo texto geográfico, recriassem, ao seu comando, as percepções e representações.

Nesse caso, como o estudante ficou relativamente livre para suas manifestações, foram explorados: formas, imagens, ícones, elementos naturais e humanos da paisagem. Nesse sentido, constatou-se que as produções descritivas (textos narrativos e poéticos) e desenhos - solicitados pelo professor, por serem mais simples e eficientes para a representação - foram as manifestações mais praticadas.

No momento intersubjetivo ocorreu a troca de experiência, sentimento e criação; dimensão fundamental para a concretização da pesquisa. A emoção, sempre presente e compartilhada, também contribuiu para a ressignificação de conteúdos geográficos. Notou-se que a objetividade foi mantida e renovada nas sistematizações sígnico-imagéticas, produções individuais e coletivas realizadas pelos alunos, movidas pelas canções; compartilhadas e reproduzidas pelos grupos e materializadas em forma de: paródias, história sem quadrinho, elaboração e interpretação de poesias, dramatizações, teatro, crônicas, depoimentos, ilustrações gráficas, confecção de cartazes, painéis, maquetes, mapas, desenhos etc., fazendo da geografia uma disciplina bem aceita e dinâmica no ambiente educativo.

Nesse sentido, pelo exposto, e vivenciado no grupo pesquisado, acredita-se que a linguagem musical pode auxiliar no ensino dos conteúdos geográficos; a música nas aulas de geografia contribui para a renovação das metodologias educacionais, pois traz, em sua essência, os elementos imprescindíveis para o desencadear de novas aspirações e motivações, que são a emoção e a razão. "A música, com sua natureza emocional e racional, alimenta a alma e o espírito, renovando a cultura humana em todo o tempo e lugar". (Correia, 2009, p.05). 


\section{REFERÊNCIAS}

ANDRÉ, Yves. Et al. Modèles Graphiques et Representations Espatiales. Paris: Anthropos, 1990.

BAILLY, Antoine et al. Géographie Régionale et Représentations. Paris: Anthropos, 1995.

BAILLY, Antoine; SCARIATI, R. L' Humanisme en Géographie. Paris: Anthropos, 1990.

BRASIL, Ministério da Educação, Secretaria de Educação Média e Tecnológica. Parâmetros curriculares nacionais: Ensino Médio. Brasília: Ministério da Educação, 1999.

BUTTIMER, A. Apreendendo o dinamismo do mundo vivido. In: CHRISTOFOLETTI, Antonio. Perspectivas da Geografia. 2. ed. Rio Claro: Difel, 1985. pp.165-194.

CAVALCANTI, Lana de Souza. Geografia, Escola e Construção de Conhecimentos. 8.ed. Campinas-SP: Papirus, 2005.

CLAVAL, Paul. As Abordagens da Geografia Cultural. In: CASTRO Iná Elias de; GOMES, Paulo César da Costa; LOBATO, Corrêa. (Organizadores). Explorações Geográficas: percursos no fim do século. Rio de Janeiro: Bertrand Brasil, 1997. pp. 89-117.

CORREIA, Marcos Antonio. Representação e Ensino - A Música nas Aulas de Geografia: Emoção e Razão nas Representações Geográficas. 2009, 115 f. Dissertação (Mestrado em Geografia ) - Universidade Federal do Paraná, Curitiba, 2009.

Música na Educação: uma possibilidade pedagógica. Revista Luminária, União da Vitória-PR, n. 6, p. 83-87. 2003. FAFI- União da Vitória. ISSN 1519-745-X

KAERCHER, Nestor André. Geografizando o Jornal e Outros Cotidianos: práticas em geografia para além do livro didático. In: CASTROGIOVANNI, Antonio Carlos; CALLAI, H. Copetti; KAERCHER, Nestor A. (Org.). Ensino de Geografia: Práticas e textualizações no cotidiano. 3. ed. Porto Alegre: Mediação, 2000. p. 135-169.

KOZEL, Salete. As representações no geográfico. In: MENDNÇA, F.; KOZEL, S. (Orgs.). Elementos de epistemologia da geografia contemporânea. Curitiba: Contexto, 2002. pp. 215-230

MERLEAU-PONTY, Maurice. Fenomenologia da percepção. (Trad.: Carlos Alberto Ribeiro de Moura). 2. ed. São Paulo: Martins Fontes, 1999. 
MOSCOVICl, Serge. Representações Sociais: investigações em psicologia social. (Trad.) Pedrinho A. Guareschi. Petrópolis, RJ: Vozes, 2005.

PARANÁ. SEED - Secretaria de Estado da Educação do Estado do Paraná. DCE Diretrizes Curriculares de Geografia p/ a Educ. Básica. Curitiba-PR, 2007. 43 p.

PPP-CEJA. Projeto Político Pedagógico - Colégio Estadual José de Anchieta. Julho de 2008. Uva/Paraná. p. 55. (SEED-PR/ Núcleo de União da Vitória).

PONTUSCHKA, Nídia Nacib. A geografia: pesquisa e ensino. In CARLOS, ANA Fani Alessandri. Novos Caminhos da Geografia. São Paulo: Contexto, pp. 111-142, 1999.

TUAN, Yi-Fu. Topofilia; um estudo da percepção. Atitudes e valores do meio ambiente. São Paulo, Difel, 1980.

São Paulo: Difel, 1983.

Espaço e lugar: A perspectiva da experiência, trad. Lívia de Oliveira.

(Recebido em 10.10.2011. Aceito em 20.04.2012) 